\title{
Mindfulness, cognitive functioning, and academic achievement in college students:the mediating role of stress
}

\author{
Emma E. McBride ${ }^{1} \cdot$ Jeffrey M. Greeson ${ }^{1}$ (D) \\ Accepted: 26 September 2021 \\ (c) The Author(s), under exclusive licence to Springer Science+Business Media, LLC, part of Springer Nature 2021
}

\begin{abstract}
Higher trait mindfulness may be associated with better cognitive functioning and academic achievement in college students. Although mediating mechanisms are unclear, lower stress levels could explain this relationship. Participants: Cross-sectional online survey ( $\mathrm{n}=534 ; 33 \%$ non-white; Apr 2018 - Sep 2019). Path analysis tested Perceived Stress as a mediator between specific facets of trait mindfulness and three measures of self-reported cognitive functioning and academic achievement: Cognitive Abilities, Cognitive Concerns, and GPA. Perceived Stress fully or partially mediated the relationship between all facets of trait mindfulness and perceived cognitive functioning. Only Decentering, however, was associated with higher GPA as a function of lower stress. Lower stress can explain the link between higher trait mindfulness and better cognitive functioning, but not necessarily academic achievement. Future research is needed to address causality, examine objective measures of cognitive functioning, and extend this explanatory model to mindfulness training.
\end{abstract}

Keywords Mindfulness $\cdot$ Cognitive functioning $\cdot$ Academic achievement $\cdot$ Stress

Many emerging adults find college life stressful. In 2019, the annual National College Health Assessment showed that the majority (77\%) of U.S. college students reported "moderate" or "high" levels of stress over the last year (American College Health Association [ACHA], 2020). Furthermore, $40 \%$ of students reported that stress negatively impacted their academic performance, outranking other common factors such as anxiety (29\%) and sleep difficulties (24\%). Previous research supports these findings, suggesting that high perceived stress in college students impairs not only self-reported academic performance, but also cognitive functioning (Palmer et al., 2014), course grades (Struthers et al., 2000), grade-point averages (Frazier et al., 2019), and college drop-out rates (Dixon \& Robinson Kurpius, 2008). This body of work implies that resilience factors, such as mindfulness, may help college students maintain strong academic and cognitive functioning by reducing stress.

Mindfulness, frequently defined as purposeful, nonjudgmental awareness of the present moment (Kabat-Zinn,

Jeffrey M. Greeson

greeson@ rowan.edu

1 Department of Psychology, College of Science and Mathematics, Rowan University, 201 Mullica Hill Road, Glassboro, NJ 08028, USA
1994), has become a well-known correlate of reduced stress and enhanced psychological well-being (de Vibe et al., 2017). This construct has been studied both as a quality cultivated through meditation practice and as a dispositional characteristic that naturally varies between individuals (Baer, 2011). There is now robust evidence supporting the efficacy of mindfulness-based interventions (MBIs) for stress reduction and overall well-being in healthy adults (Chiesa \& Serretti, 2009) and in students (Bamber \& Schneider, 2015; Greeson et al., 2015; Oman et al., 2008), as well as a growing body of evidence linking dispositional or "trait" mindfulness to lower perceived stress in adults who have never formally meditated (Mesmer-Magnus et al., 2017).

To date, much of the literature on mindfulness, stress, and cognitive functioning in college students has focused on enhancing cognitive or academic performance through meditation training. For example, several preliminary trials have found positive effects of MBIs offered in college settings on working memory and GRE reading-comprehension scores (Mrazek et al., 2013), retention of course material (Ching et al., 2015), executive control (Schanche et al., 2020), GPA (Napora, 2013), and quiz performance (CalmaBirling \& Gurung, 2017). There is also some indication that even brief mindfulness exercises have immediate positive 
effects on memory performance (Eisenbeck et al., 2018; Lloyd et al., 2016). However, other trials have noted that, despite improved short-term performance on quizzes and cognitive measures of memory, the effects of these interventions do not always translate to improved long-term academic performance (Baranski \& Was, 2019; Calma-Birling \& Gurung, 2017; Yamada \& Victor, 2012).

While it appears that mindfulness practice may improve cognitive functioning and academic performance in college students, very little is known about the association between trait mindfulness and these abilities in students who have not received meditation instruction. Prior to beginning a classroom-based mindfulness program, Napora (2013) found a moderate positive association between overall trait mindfulness and self-reported cognitive engagement, as well as small correlations between two facets of trait mindfulness (Acting with Awareness and Nonreactivity) and GPA. To our knowledge, there have been no other direct examinations of trait mindfulness, cognitive functioning, and academic achievement in college students beyond this one unpublished dissertation.

Because MBIs are presumed to influence outcomes via increased trait mindfulness (Shapiro et al., 2011), discerning the relationship between trait mindfulness, cognitive functioning, and academic performance in college students could help to inform intervention targets and elucidate mechanisms of change in future trials. In addition, because trait mindfulness is multifaceted, can be divided into subscales, and can be interpreted differently depending on meditation experience (Gu et al., 2016), it is unclear which specific facets of trait mindfulness are most important in explaining academicrelated outcomes. There is some indication, for example, that certain aspects of mindfulness, such as focused attention, nonreactivity, acting with awareness, and decentering, may drive the positive relationship between mindfulness training and improved cognitive functioning over and above other facets (Chiesa et al., 2011; Kaiser et al., 2015; Napora, 2013). Therefore, to better understand which aspects of trait mindfulness are most strongly tied to cognitive functioning and academic performance, the present study examined one unidimensional measure of trait mindfulness (Cognitive and Affective Mindfulness Scale - Revised; CAMS-R) as well as several specific facets of trait mindfulness: Acting with Awareness, Non-Reactivity, Non-Judging, Describing, and Decentering.

In addition, more closely examining trait mindfulness and its facets may clarify potential mediators between mindfulness and better cognitive functioning/academic performance. For example, MBIs frequently reduce perceived stress, and lower stress levels may mediate the relationship between mindfulness and improved psychological well-being (Carmody \& Baer, 2008; Gu et al., 2015). Among college students, a growing body of research suggests trait mindfulness may predict lower perceived stress (Lyvers et al., 2014; Medvedev et al., 2018; Palmer \& Rodger, 2009; Zimmaro et al., 2016) and, as reviewed above, lower perceived stress may predict better cognitive functioning and academic performance. Given the association between trait mindfulness and stress on the one hand, and between stress and cognitive functioning/academic performance on the other, we hypothesize that the positive effect of trait mindfulness on these variables may be party explained by lower stress. Indeed, both Salmon et al. (2011) and Creswell and Lindsay (2014) offer theoretical models of mindfulness which suggest that being more mindful, in part, facilitates a capacity to manage stressors more effectively, thereby decreasing perceived stress and facilitating attentional processes.

Building on mixed findings from previous research, this analysis aimed to replicate associations between several facets of trait mindfulness and self-reported cognitive functioning and academic performance in a large, diverse sample of college students. Moreover, to directly examine the mechanisms of mindfulness, we also tested whether perceived stress mediates the relationship between trait mindfulness and cognitive functioning and academic performance.

\section{Methods}

\section{Design}

Cross-sectional online survey study, conducted from April 2018 - September 2019.

\section{Participants}

Undergraduate students aged 18-64 were recruited from introductory psychology courses, in which participation in research counted toward course credit. Other students were recruited via in-person announcements to classes, emails, and flyers. Sample characteristics are shown in Table 1.

\section{Procedure}

The Qualtrics survey consisted of an informed consent page followed by demographic and self-report questionnaires. Once completed, the anonymous survey concluded with a debriefing page that then linked to a separate survey used to collect identifying information for course credit, if applicable. The protocol was approved by the university Institutional Review Board and was carried out in accordance with the Declaration of Helsinki. 
Table 1 Sample Characteristics

\begin{tabular}{|c|c|}
\hline Age (yrs) & Median $=19, \mathrm{IQR}=18-21$ \\
\hline \multicolumn{2}{|l|}{ Gender } \\
\hline Female & $\mathrm{n}=347(65 \%)$ \\
\hline Male & $\mathrm{n}=179(34 \%)$ \\
\hline Transgender & $\mathrm{n}=1(<1 \%)$ \\
\hline Gender Variant/Non-Conforming & $\mathrm{n}=6(1 \%)$ \\
\hline Not Listed & $\mathrm{n}=1(<1 \%)$ \\
\hline \multicolumn{2}{|l|}{ Race } \\
\hline White & $\mathrm{n}=359(67 \%)$ \\
\hline Black & $\mathrm{n}=71(13 \%)$ \\
\hline Native American or American Indian & $\mathrm{n}=1(<1 \%)$ \\
\hline Asian/Pacific Islander & $\mathrm{n}=36(7 \%)$ \\
\hline Multiracial & $\mathrm{n}=29(5 \%)$ \\
\hline Other Race & $\mathrm{n}=32(6 \%)$ \\
\hline Prefer Not to Answer & $\mathrm{n}=6(1 \%)$ \\
\hline \multicolumn{2}{|l|}{ Annual Household Income } \\
\hline$>\$ 10,000$ & $\mathrm{n}=60(11 \%)$ \\
\hline$\$ 10,00-\$ 30,00$ & $\mathrm{n}=48(9 \%)$ \\
\hline$\$ 30,000-\$ 50,000$ & $\mathrm{n}=57(11 \%)$ \\
\hline$\$ 50,000-\$ 100,000$ & $\mathrm{n}=85(16 \%)$ \\
\hline$\$ 100,000-\$ 150,000$ & $\mathrm{n}=79(15 \%)$ \\
\hline$\$ 150,000-200,000$ & $\mathrm{n}=38(7 \%)$ \\
\hline More than $\$ 200,000$ & $\mathrm{n}=19(4 \%)$ \\
\hline Prefer Not to Answer & $\mathrm{n}=148(28 \%)$ \\
\hline \multicolumn{2}{|l|}{ Year In College } \\
\hline 1st year & $\mathrm{n}=197(37 \%)$ \\
\hline 2nd year & $\mathrm{n}=151(28 \%)$ \\
\hline 3rd year & $\mathrm{n}=98(18 \%)$ \\
\hline 4th year & $\mathrm{n}=67(13 \%)$ \\
\hline 5 th year & $\mathrm{n}=7(1 \%)$ \\
\hline Other & $\mathrm{n}=12(2 \%)$ \\
\hline Prefer Not to Answer & $\mathrm{n}=2(<1 \%)$ \\
\hline Prior Meditation Experience (yrs) & $\bar{x}=3.16$, range $=0-25, n=241(43 \%)$ \\
\hline
\end{tabular}

\section{Measures}

\section{Mindfulness}

Cognitive and Affective Mindfulness Scale - Revised (CAMS-R; Feldman et al., 2007) The CAMS-R is a unidimensional trait mindfulness measure which yields a total score meant to be independent of any particular type of mindfulness training. The summed total score ranges from 12 to 48, with higher scores reflecting greater mindfulness of thoughts and feelings.

Five Facet Mindfulness Questionnaire (FFMQ - Short Form; Gu et al., 2016) The FFMQ assesses an individual's self-rated mindfulness across five domains: Observing, Describing, Acting with Awareness, Non-Judging of Inner Experience, and Non-Reactivity to Inner Experience. Given poor reliability for the Observing subscale $(\alpha=.58)$ and $\mathrm{Gu}$ et al.'s (2016) suggestion that the Observing subscale may not be valid in meditation naïve populations, this facet was omitted from further analysis. Summed scores for each facet range from 3 to 15, with higher scores indicating more of the facet being measured.

Decentering Subscale of the Experiences Questionnaire (Fresco et al., 2007) The Decentering subscale measures the degree to which respondents feel they can "step back" and observe thoughts and feelings as temporary, rather than as true reflections of the self. Summed scores for this measure range from 11 to 55 , with higher scores indicating greater capacity to decenter. 
Fig. 1 Hypothesized mediation model connecting Trait Mindfulness, Perceived Stress, and Cognitive Functioning/Academic Achievement, controlling for Gender, Race, and Meditation Experience

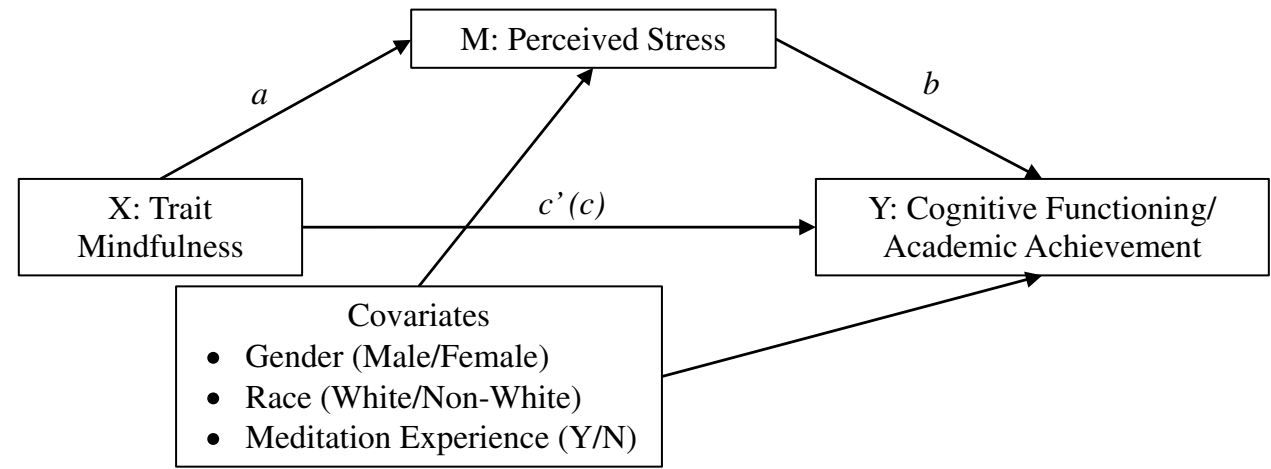

Stress

Perceived Stress Scale (PSS-10; Cohen \& Janicki-Deverts, 2012) The PSS assesses perceived stress level over the past 30 days. Summed total scores range from 0 to 40, with higher scores indicating greater perceived stress.

\section{Cognitive Functioning}

Applied Cognition - Cognitive Abilities PROMIS Short form 6a This 6-item measure assesses self-perceived mental sharpness, memory, efficiency, and concentration, during the past 7-days.

\section{Applied Cognition - Cognitive Concerns PROMIS Short form} 6a Similarly, this 6-item measure assesses perceived difficulty with core cognitive functions including slowed thinking (processing speed), set shifting (executive functioning), and trouble concentrating. Of note, higher scores indicate fewer cognitive concerns. Therefore, higher scores on each cognition scale indicate better cognitive functioning. The two scales are not collinear $(r=.42)$ and are normed relative to a nationally representative sample (Mean $(\mathrm{SD})=50 \mathrm{~T}(10 \mathrm{~T}))$.

Academic Performance Academic performance was measured using self-reported grade point average (GPA) to two decimal places on a 4.00 -point scale.

\section{Statistical Analysis Plan}

All hypotheses were addressed by first assessing psychometrics, univariate distributions, graphics, and assumptions (Fife, 2020). Results were interpreted using parameter estimates, confidence intervals, and effect sizes, in addition to p-values.

Mediation analyses controlled for factors believed to influence college stress, cognitive functioning, and academic performance: gender, race, and prior meditation experience
(See Fig. 1). ${ }^{1}$ Assumptions of normality, linearity, and homoskedasticity were checked prior to each analysis. Analyses were conducted in accordance with Hayes (2013) such that $\mathrm{X}=$ Mindfulness, $\mathrm{Y}=$ Cognitive Functioning/Academic Achievement, and $M=$ Perceived Stress (see Fig. 1). All analyses were completed using SPSS Process Macro (Hayes, 2013). Evidence for mediation was inferred given a statistically significant Sobel test of the indirect effect $(a b)$ and a bootstrapped confidence interval (5000 bootstrap samples) that did not contain zero. To correct for multiple comparisons, a familywise alpha adjustment was applied to inferential tests for mediation $(\mathrm{p}=.05$ divided by a family of three primary outcome measures: Cognitive Abilities, Cognitive Concerns, and GPA), resulting in critical $\alpha=.017$ (Holland \& Copenhaver, 1988).

\section{Results}

Means, standard deviations, reliability statistics, and bivariate correlations for all study variables are presented in Table 2. All were within the expected range for a college student sample. GPA was squared to correct for negative skew (16 cases of GPA below 2.0).

\section{Correlations}

As expected, all mindfulness measures were negatively correlated with Perceived Stress $(-.686<\mathrm{r}<-.182$, all p's $<.01)$. All facets of mindfulness except Non-Reactivity

\footnotetext{
$\overline{1}$ Household income was also a planned control variable, but $28 \%$ of the sample declined to provide a household income estimate. Spearman's rank correlation coefficients for income and GPA indicated no relationship, so this control variable was excluded from further analysis to avoid substantially reducing the total sample size. There was a small positive correlation between income and both cognitive concerns and cognitive abilities, therefore models with these outcome variables were run both with $(\mathrm{n}=534)$ and without $(\mathrm{n}=384)$ income. Results were equivalent in both cases.
} 
Table 2 Bivariate Correlations between Trait Mindfulness and Cognitive Functioning Variables

\begin{tabular}{|c|c|c|c|c|c|c|c|c|c|c|}
\hline Measures & 1 & 2 & 3 & 4 & 5 & 6 & 7 & 8 & 9 & 10 \\
\hline 1. CAMS-R & - & & & & & & & & & \\
\hline 2. FFMQ-DES & $.481 * *$ & - & & & & & & & & \\
\hline 3. FFMQ-AWA & $.373 * *$ & $.204 * *$ & - & & & & & & & \\
\hline 4. FFMQ-NJ & $.461 * *$ & $.318 * *$ & $.414 * *$ & - & & & & & & \\
\hline 5. FFMQ-NR & $.241 * *$ & $.225^{* *}$ & $-.111 *$ & -.056 & - & & & & & \\
\hline 6. Decentering & $.697 * *$ & $.417 * *$ & $.280 * *$ & $.409 * *$ & $.272 * *$ & - & & & & \\
\hline 7. PSS & $-.686^{* *}$ & $-.321 * *$ & $-.367 * *$ & $-.483 * *$ & $-.182 * *$ & $-.598 * *$ & - & & & \\
\hline 8. Cognitive Abilities & $.326 * *$ & $.222 * *$ & $.135^{* *}$ & $.178^{* *}$ & .076 & $.229 * *$ & $-.320 * *$ & - & & \\
\hline 9. Cognitive Concerns & $.509 * *$ & $.293 * *$ & $.345^{* *}$ & $.330 * *$ & .000 & $.392 * *$ & $-.523 * *$ & $.420 * *$ & - & \\
\hline 10. GPA & .039 & .018 & -.006 & .026 & .052 & -.006 & -.062 & .064 & .071 & N/A \\
\hline $\begin{array}{l}\text { Mean } \\
\text { (SD) }\end{array}$ & $31.0(6.2)$ & $9.6(2.7)$ & $9.3(2.4)$ & $10.0(3.0)$ & $9.1(2.5)$ & $37.5(7.5)$ & $19.5(7.0)$ & $49.0(8.7)$ & $46.5(8.6)$ & $3.2(0.6)$ \\
\hline $\mathbf{N}$ & 516 & 533 & 529 & 531 & 530 & 517 & 524 & 534 & 534 & 500 \\
\hline$\alpha$ & 0.84 & 0.80 & 0.69 & 0.83 & 0.69 & 0.90 & 0.87 & 0.92 & 0.93 & N/A \\
\hline
\end{tabular}

Note. $* \mathrm{p}<.05, * * \mathrm{p}<.01$, two-tailed; $\mathrm{M}=$ Mean; $\mathrm{SD}=$ Standard deviation; CAMS- $\mathrm{R}=$ Cognitive and Affective Mindfulness Scale-Revised; DES=Describing; AWA = Acting with Awareness; NJ = Non-Judging; NR = Non-Reactivity; PSS=Perceived Stress Scale

were positively correlated with both Cognitive Abilities $(.135<\mathrm{r}<.326$, all p's $<.01)$ and Cognitive Concerns $(.293<\mathrm{r}<.509$, all p's $<.01)$. As noted, correlations between mindfulness and Cognitive Concerns were positive because higher scores on the latter indicate fewer concerns. Similarly, Perceived Stress correlated negatively with Cognitive Abilities and Cognitive Concerns, as hypothesized. Contrary to our expectations, neither trait mindfulness nor Perceived Stress was correlated with GPA.

\section{The Mediating Effect of Perceived Stress}

Results of all simple mediation analyses conducted using ordinary least squares path analysis are depicted in Fig. 2. Each model controlled for Gender, Race, and Meditation Experience (not depicted). Inferential tests for the indirect effects $(a b)$ are reported in Table 3 . Regarding Cognitive Abilities, all models provided support for perceived stress as a mediator, indicated by a significant Sobel test for the indirect effect $(.150<a b<.405$, all p's $<.01)$ and bootstrapped confidence intervals that did not contain zero. Similarly, for Cognitive Concerns all models showed a significant Sobel test $(.317<a b<.625$, all p's $<.001)$, and bootstrapped confidence intervals for the indirect effect did not contain zero. There was one unanticipated finding involving the relationship between Non-Reactivity and Cognitive Concerns. Specifically, after accounting for the expected indirect effect linking higher Non-Reactivity with fewer Cognitive Concerns via lower Perceived Stress, there emerged an additional, unexpected direct effect, such that after accounting for the mediating effect of stress, higher residual Non-Reactivity was directly associated with more Cognitive Concerns, even though the bivariate association was null. Lastly, for
GPA, Perceived Stress mediated the association between higher Decentering and higher GPA $(a b=.042, \mathrm{p}=.011$, $\mathrm{CI}=.008-.079)$, as expected, although no other facets of trait mindfulness predicted GPA, directly or indirectly.

\section{Discussion}

This study examined associations between several facets of trait mindfulness, stress, cognitive functioning, and academic achievement in a large, demographically diverse sample of college students. The results are the first to our knowledge to support the hypothesis that lower stress levels can mediate the association between higher trait mindfulness and greater perceived cognitive functioning and academic achievement.

All facets of trait mindfulness were significantly associated with both Cognitive Abilities and Cognitive Concerns, via Perceived Stress. This provides robust support for lower stress as a potential mechanism linking several different core qualities of trait mindfulness with better perceived cognitive functioning in students. In addition, the size of the indirect effect was larger for all models predicting Cognitive Concerns than for those predicting Cognitive Abilities. This may indicate that high stress is a particularly important mechanism by which low mindfulness associates with difficulty concentrating, set shifting, and processing information.

The indirect effect of trait mindfulness on cognitive functioning was also stronger for some facets of mindfulness than others. Specifically, Perceived Stress fully mediated the associations between Acting with Awareness, Non-Judging, and Decentering in models predicting Cognitive Abilities. Indirect effects for the same facets, with the addition of 

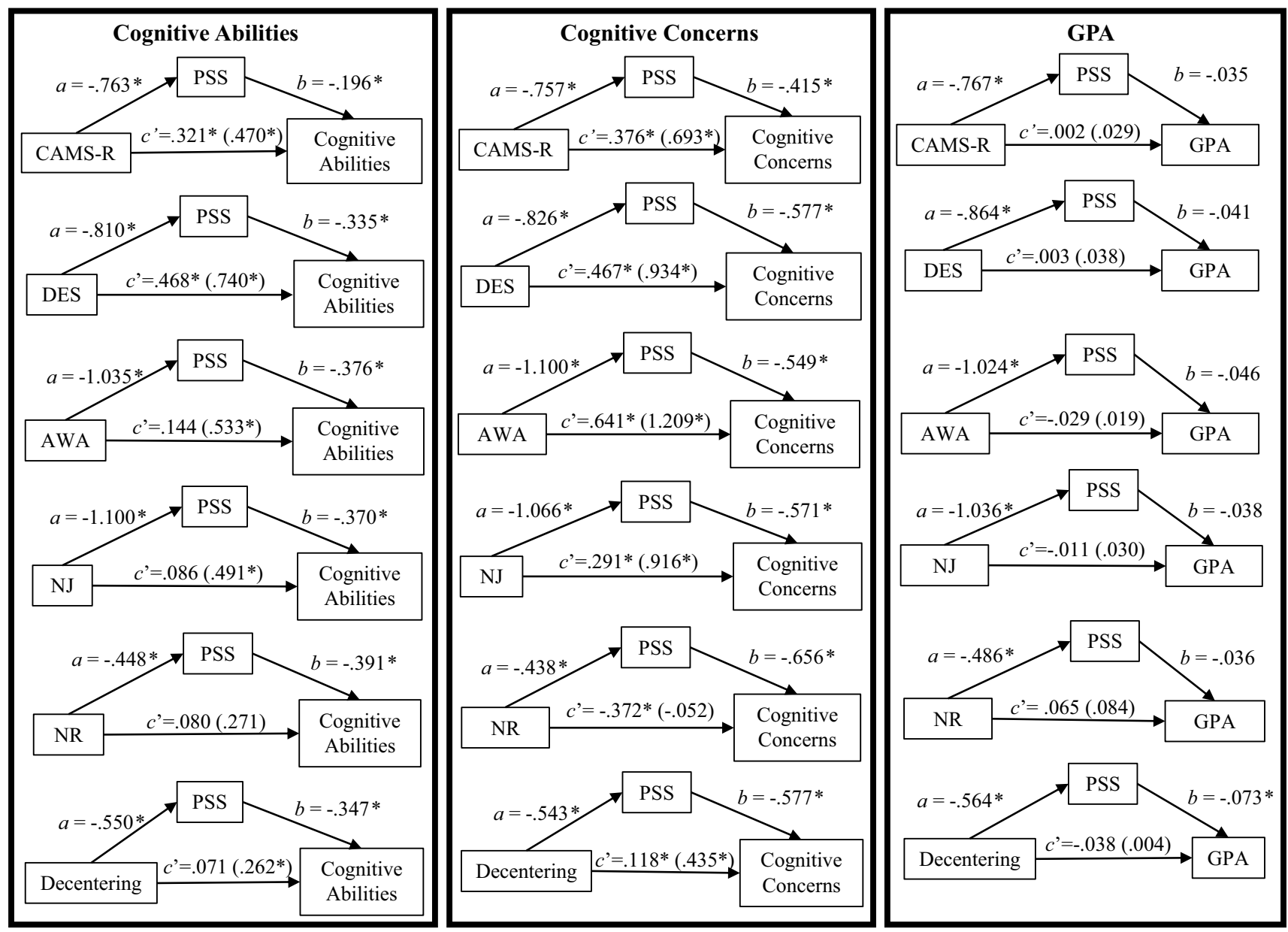

Fig. 2 Simple mediation models predicting Cognitive Abilities, Cognitive Concerns, and GPA from facets of trait mindfulness, with Perceived Stress as a mediator. Cognitive Abilities and Cognitive Con- cerns are both scored such that higher levels indicate better cognitive functioning. Covariates (Gender, Race, Meditation Experience) are not depicted. $* \mathrm{p}<.017$ (familywise adjusted alpha)
Describing, were also strongest in models predicting Cognitive Concerns, although they indicated partial, rather than full, mediation. This pattern of findings on specific facets of trait mindfulness suggests it is possible that students' ability to (1) pay attention to what they're doing, (2) mindfully accept their thoughts and feelings, and (3) observe their internal state from a wider perspective is directly associated with lower stress and, in turn, better cognitive functioning.

There was one unexpected finding for the relationship between Non-Reactivity and Cognitive Concerns. On the one hand, higher Non-Reactivity was associated with fewer Cognitive Concerns as a function of lower Perceived Stress, as predicted. On the other hand, after accounting for the expected mediating effect of Perceived Stress, there emerged a significant direct effect by which higher Non-Reactivity also associated with more Cognitive Concerns. This counterintuitive finding could potentially be explained by one or more additional mediators that were not included in our explanatory model. Differences in task engagement, for example, could potentially explain why more "non-reactive" students who are generally inclined to "step back," "just notice," and "let go" of distressing thoughts or images may be less engaged in school-related tasks, which, in turn, may correlate with more Cognitive Concerns. Overall, the pattern of mediation findings observed was consistent with a stress-health model of mindfulness (Salmon et al., 2011) and mindfulness stress buffering theory (Creswell \& Lindsay, 2014), both of which suggest that mindfulness may facilitate students' capacity to self-regulate and effectively cope with stress, thereby improving processing speed, executive functioning, concentration, memory and perceived mental sharpness.

While results provide support for lower perceived stress as a mechanism of mindfulness, neither the stress-health model of mindfulness nor mindfulness stress buffering theory specifically address perceived cognitive functioning as an aspect of well-being mindfulness may impact via stress. This is a distinct variable that does not necessarily map 
Table 3 The Mediating Effect of Perceived Stress

\begin{tabular}{lllll}
\hline Outcome Variable & Predictor & Indirect Effect $(a b)$ & $95 \%$ CI (lower) & $95 \%$ CI (upper) \\
\hline Cognitive Abilities & CAMS-R & $.150^{*}$ & .043 & .263 \\
& FFMQ-DES & $.272^{* *}$ & .166 & .392 \\
& FFMQ-AWA & $.389^{* *}$ & .249 & .554 \\
& FFMQ-NJ & $.405^{* *}$ & .254 & .574 \\
& FFMQ-NR & $.191^{* *}$ & .079 & .311 \\
& Decentering & $.191^{* *}$ & .122 & .267 \\
Cognitive Concerns & CAMS-R & $.317^{* *}$ & .219 & .418 \\
& FFMQ-DES & $.467^{* *}$ & .321 & .623 \\
& FFMQ-AWA & $.568^{* *}$ & .404 & .738 \\
& FFMQ-NJ & $.625^{* *}$ & .468 & .508 \\
& FFMQ-NR & $.320^{* *}$ & .135 & .396 \\
& Decentering & $.317^{* *}$ & .241 & .077 \\
& CAMS-R & .027 & -.024 & .078 \\
GPA & FFMQ-DES & .034 & -.009 & .104 \\
& FFMQ-AWA & .048 & -.004 & .099 \\
& FFMQ-NJ & .041 & -.014 & .052 \\
& FFMQ-NR & .019 & -.006 & .079 \\
\hline
\end{tabular}

Note. $* \mathrm{p}<.017, * * \mathrm{p}<.001$. CAMS-R $=$ Cognitive and Affective Mindfulness Scale-Revised; $\mathrm{DES}=$ Describing; $\mathrm{AWA}=$ Acting with Awareness; $\mathrm{NJ}=$ Non-Judging; $\mathrm{NR}=$ Non-Reactivity directly onto objective cognitive functioning or academic achievement. The positive correlations between all measures of trait mindfulness and perceived cognitive functioning found in this analysis are consistent with one previous study, which found positive correlations between all FFMQ facets and self-reported "cognitive engagement," or students' perceived attention to and persistence with learning (Napora, 2013). We also found increased Perceived Stress was associated with worse perceived cognitive functioning, at medium to large effect size. This is consistent with students' perception that stress negatively impacts their academic performance (ACHA, 2020) and objective neurocognitive data showing perceived stress negatively impacts performance on cognitive tasks (Palmer et al., 2014). However, because perceived cognitive functioning does not always strongly predict neurocognitive performance in young adults (Dhillon et al., 2020; Lin et al., 2019), additional research is needed to assess whether the hypothesized model describes the relationship between trait mindfulness, stress, and both subjective and objective measures of cognitive functioning. Similarly, given the myriad determinants of academic achievement that ultimately impact GPA, including study habits (Plant et al., 2005), self-efficacy (Brown et al., 2008), high school achievement (Hannon, 2014), general intelligence (Pluck et al., 2016), and burnout (May et al., 2015), it perhaps was not surprising that most facets of trait mindfulness, except Decentering, did not significantly explain variance in GPA. Although one unpublished dissertation study (Napora, 2013) documented small associations between certain facets of trait mindfulness (Acting with Awareness and Non-Reactivity) and GPA, we were unable to replicate that finding, perhaps due to demographic differences in study samples or reliance on self-reported GPA.

Finally, these results are also relevant to student stress and resilience during the COVID-19 pandemic. American college students are reporting increased perceived stress as a consequence of COVID-19 and related restrictions on their academic and social lives (Charles et al., 2021). As a consequence, students describe increased difficulty concentrating due to pandemic-related stress $(89 \%$ of students surveyed), as well increased concern about their academic performance (82\%; Son et al., 2020). Worse still, less than half of college students $(43 \%)$ in a large $(n=882)$ recent survey report being able to mitigate the impact of pandemicrelated stress on their personal and academic lives (Wang et al., 2020). However, high trait mindfulness appears to be associated with lower pandemic stress and more positive coping strategies in students (Dillard \& Meier, 2021), making it a potential resilience factor that may extend to cognitive and academic functioning. Indeed, a recent trial of a brief mindfulness-based intervention tailored to college students (Koru Mindfulness) showed not only decreased stress following mindfulness training, but also improved performance on an objective measures of attention, as compared a waitlist control group (Weis et al., 2021). The mediation model supported by the present analysis may help explain these results: as college students learn mindfulness meditation, they likely become more mindful, resulting in lower 
stress and, in turn, improved cognitive performance. Taken together, these recent data help us understand how both trait mindfulness as well as mindfulness training may help students manage stress reactions and preserve cognitive functioning, especially in a time of pandemic-related stress and uncertainty.

\section{Strengths and Limitations}

The present study was conducted using cross-sectional survey data from a large college student sample. Although the sample demographics were representative of the student population across gender and race, our sample primarily included freshmen and students taking introductory courses in psychology, as students in these classes were offered course credit upon completing the survey. Generalizability to older college students and students who are not interested in psychology is therefore limited. Furthermore, although this analysis can inform future longitudinal and/or intervention research, it is not possible to infer causality between mindfulness, stress, and cognitive functioning because the data are cross-sectional. Relatedly, we tested a theoreticallyinformed mediation model, but there is some indication that the relationship between trait mindfulness and perceived stress is bidirectional, such that high mindfulness lowers stress, but lower stress also increases mindfulness (Zimmaro et al., 2016). This being the case, mindfulness may mediate the association between perceived stress and cognitive functioning in a bidirectional feedback process wherein both variables influence each other to impact everyday functioning and well-being. Potential bidirectional relationships between mindfulness and stress can be investigated in future longitudinal studies, and in intervention research on stressmanagement programs to improve cognitive performance via increased mindfulness in college students. Lastly, this study tested only one hypothesized mediator - perceived stress. There are likely many more mechanisms of mindfulness. For example, one mindfulness training study in college students found that improvements in cognitive performance (working memory) and test performance (GRE scores) were mediated by reduced mind wandering, but only among those participants who were prone to distraction pre-intervention (Mrazek et al., 2013). Although we cannot assume that models describing mindfulness training will generalize to trait mindfulness in a mostly meditation-naïve population, it is likely that additional variables, like mind wandering, drive the relationship between trait mindfulness and cognitive functioning. In fact, the majority of models tested in this study support stress as a partial, not full, mediator of the relationship between trait mindfulness and cognitive functioning. Other potential mediators could include rumination (Schanche et al., 2020) and attention monitoring (Lindsay $\&$ Creswell, 2017). Finally, as discussed above, perceived cognitive functioning is often distinct from objectively measured cognitive performance. Future research is needed to confirm whether the mediation model tested here also describes the relationship between trait mindfulness, stress, and objective measures of cognitive functioning.

This study also had several methodological strengths. We used reliable, validated self-report measures, controlled for confounds thought to impact trait mindfulness and academic achievement, investigated specific facets of mindfulness individually, and analyzed a large, demographically diverse sample of American college students. In addition, this study makes an important contribution to the literature by testing a theoretically informed explanatory model of trait mindfulness in college students. This is consistent with recent calls in the field to shift focus toward underlying mechanisms linking specific aspects of mindfulness (e.g. awareness and acceptance) with specific effects (e.g. cognition, affect, health; Lindsay \& Creswell, 2017). Indeed, several recently published mindfulness-based intervention trials with college students have demonstrated that brief mindfulness practice can improve later cognitive/academic performance (Baranski \& Was, 2019; Calma-Birling \& Gurung, 2017; Mrazek et al., 2013) and perceived learning ability (Yamada \& Victor, 2012), but analysis of potential mediators has been limited. Our results reveal that future intervention research on this topic should test decreased stress as a causal mechanism driving the effect of mindfulness training on cognitive performance.

\section{Conclusion}

We identified a specific mechanism, lower perceived stress, by which higher trait mindfulness and its facets explain better cognitive functioning in college students. Contrary to our hypothesis, trait mindfulness generally did not relate to academic achievement (GPA), except for a significant mediating effect for Decentering. While we could not address causality, our results document empirical links between mindfulness, stress, and cognitive functioning that can be tested longitudinally. Future research may also investigate whether high trait mindfulness improves cognitive functioning by reducing stress, or impacting other potential mechanisms of mindfulness, such as reduced mind wandering. In addition, researchers can use neurocognitive testing to objectively measure cognitive functioning, while also replicating results for perceived cognitive functioning. Lastly, future research should explore whether this mechanistic model generalizes to mindfulness training, as a growing body of literature suggests that mindfulness training increases trait mindfulness, decreases stress, and improves cognitive functioning, all of which, together, could support optimal academic achievement in college students. 
Acknowledgments For assistance with online data collection, survey management, and quality assurance, we thank undergraduate research assistants Emily Barbera, Tyler Henderson, Mikela Janal, Victoria Kloster, and Jared Richards. For assistance with data cleaning and quality assurance, we thank graduate student Gabrielle Chin.

Availability of Data and Material The data that support the findings of this study are publicly available from Rowan Digital Works: https:// rdw.rowan.edu/datasets/2/

Code Availability The syntax used to support the analyses in this study are available from the corresponding author, JMG, upon reasonable request.

Funding No funding was received for conducting this study.

\section{Declarations}

Conflicts of Interest/Competing Interests The authors have no relevant financial or non-financial interests to disclose.

Ethics Approval This study was performed in line with the principles of the Declaration of Helsinki. Approval was granted by the Institutional Review Board (IRB) of Rowan University.

Consent to Participate Informed consent was obtained from all individual participants included in the study.

Consent for Publication The authors affirm that human research participants provided informed consent for publication of their de-identified survey data.

\section{References}

American College Health Association. (2020). American college health association - National College Health Assessment III: Undergraduate student reference group executive summary fall 2019. American College Health Association.

Baer, R. A. (2011). Measuring mindfulness. Contemporary Buddhism, 12(1), 241-261. https://doi.org/10.1080/14639947.2011.564842

Bamber, M., \& Schneider, J. (2015). Mindfulness-based meditation to decrease stress and anxiety in college students: A narrative synthesis of the research. Educational Research Review, 18, 1-32. https://doi.org/10.1016/j.edurev.2015.12.004

Baranski, M. F. S., \& Was, C. A. (2019). Can mindfulness meditation improve short-term and long-term academic achievement in a higher-education course? College Teaching, 67(3), 188-195. https://doi.org/10.1080/87567555.2019.1594150

Brown, S. D., Tramayne, S., Hoxha, D., Telander, K., Fan, X., \& Lent, R. W. (2008). Social cognitive predictors of college students' academic performance and persistence: A meta-analytic path analysis. Journal of Vocational Behavior, 72(3), 298-308. https://doi. org/10.1016/j.jvb.2007.09.003

Calma-Birling, D., \& Gurung, R. A. R. (2017). Does a brief mindfulness intervention impact quiz performance? Psychology Learning \& Teaching, 16(3), 323-335. https://doi.org/10.1177/1475725717 712785

Carmody, J., \& Baer, R. A. (2008). Relationships between mindfulness practice and levels of mindfulness, medical and psychological symptoms and well-being in a mindfulness-based stress reduction program. Journal of Behavioral Medicine, 31(1), 23-33. https:// doi.org/10.1007/s10865-007-9130-7

Charles, N. E., Strong, S. J., Burns, L. C., Bullerjahn, M. R., \& Serafine, K. M. (2021). Increased mood disorder symptoms, perceived stress, and alcohol use among college students during the COVID-19 pandemic. Psychiatry Research, 296, 113706. https:// doi.org/10.1016/j.psychres.2021.113706

Chiesa, A., \& Serretti, A. (2009). Mindfulness-based stress reduction for stress management in healthy people: A review and meta-analysis. The Journal of Alternative and Complementary Medicine, 15(5), 593-600. https://doi.org/10.1089/acm.2008.0495

Chiesa, A., Calati, R., \& Serretti, A. (2011). Does mindfulness training improve cognitive abilities? A systematic review of neuropsychological findings. Clinical Psychology Review, 31(3), 449-464. https://doi.org/10.1016/j.cpr.2010.11.003

Ching, H.-H., Koo, M., Tsai, T.-H., \& Chen, C.-Y. (2015). Effects of a mindfulness meditation course on learning and cognitive performance among university students in Taiwan. Evidence-based Complementary and Alternative Medicine, 2015, 254358. https:// doi.org/10.1155/2015/254358

Cohen, S., \& Janicki-Deverts, D. (2012). Who's stressed? Distributions of psychological stress in the United States in probability samples from 1983, 2006, and 2009. Journal of Applied Social Psychology, 42(6), 1320-1334. https://doi.org/10.1111/j.15591816.2012.00900.x

Creswell, J. D., \& Lindsay, E. K. (2014). How does mindfulness training affect health? A mindfulness stress buffering account. Current Directions in Psychological Science, 23(6), 401-407. https://doi. org/10.1177/0963721414547415

de Vibe, M., Bjørndal, A., Fattah, S., Dyrdal, G. M., Halland, E., \& Tanner-Smith, E. E. (2017). Mindfulness-based stress reduction (MBSR) for improving health, quality of life and social functioning in adults: A systematic review and meta-analysis. Campbell Systematic Reviews, 13(1), 1-264. https://doi.org/10.4073/csr. 2017.11

Dhillon, S., Videla-Nash, G., Foussias, G., Segal, Z. V., \& Zakzanis, K. K. (2020). On the nature of objective and perceived cognitive impairments in depressive symptoms and real-world functioning in young adults. Psychiatry Research, 287, 112932. https://doi.org/10.1016/j. psychres.2020.112932

Dillard, A. J., \& Meier, B. P. (2021). Trait mindfulness is negatively associated with distress related to COVID-19. Personality and Individual Differences, 179, 110955. https://doi.org/10.1016/j. paid.2021.110955

Dixon, S., \& Robinson Kurpius, S. (2008). Depression and college stress among university undergraduates: Do mattering and selfesteem make a difference? Journal of College Student Development, 49, 412-424. https://doi.org/10.1353/csd.0.0024

Eisenbeck, N., Luciano, C., \& Valdivia-Salas, S. (2018). Effects of a focused breathing mindfulness exercise on attention, memory, and mood: The importance of task characteristics. Behaviour Change, 35(1), 54-70. https://doi.org/10.1017/bec.2018.9

Feldman, G., Hayes, A., Kumar, S., Greeson, J., \& Laurenceau, J.-P. (2007). Mindfulness and emotion regulation: The development and initial validation of the Cognitive and Affective Mindfulness Scale-Revised (CAMS-R). Journal of Psychopathology and Behavioral Assessment, 29(3), 177. https://doi.org/10.1007/ s10862-006-9035-8

Fife, D. (2020). The eight steps of data analysis: A graphical framework to promote sound statistical analysis. Perspectives on Psychological Science, 15(4), 1054-1075. https://doi.org/10.1177/ 1745691620917333

Frazier, P., Gabriel, A., Merians, A., \& Lust, K. (2019). Understanding stress as an impediment to academic performance. Journal of American College Health, 67(6), 562-570. https://doi.org/10.1080/ 07448481.2018 .1499649 
Fresco, D. M., Moore, M. T., van Dulmen, M. H. M., Segal, Z. V., Ma, S. H., Teasdale, J. D., \& Williams, J. M. G. (2007). Initial psychometric properties of the experiences questionnaire: Validation of a self-report measure of decentering. Behavior Therapy, 38(3), 234-246. https://doi.org/10.1016/j.beth.2006.08.003

Greeson, J. M., Toohey, M. J., \& Pearce, M. J. (2015). An adapted, four-week mind-body skills group for medical students: Reducing stress, increasing mindfulness, and enhancing self-care. EXPLORE, 11(3), 186-192. https://doi.org/10.1016/j.explore. 2015.02.003

Gu, J., Strauss, C., Bond, R., \& Cavanagh, K. (2015). How do mindfulness-based cognitive therapy and mindfulness-based stress reduction improve mental health and wellbeing? A systematic review and meta-analysis of mediation studies. Clinical Psychology Review, 37, 1-12. https://doi.org/10.1016/j.cpr.2015.01.006

Gu, J., Strauss, C., Crane, C., Barnhofer, T., Karl, A., Cavanagh, K., \& Kuyken, W. (2016). Examining the factor structure of the 39-item and 15 -item versions of the five facet mindfulness questionnaire before and after mindfulness-based cognitive therapy for people with recurrent depression. Psychological Assessment, 28(7), 791-802. https:// doi.org/10.1037/pas0000263

Hannon, B. (2014). Predicting college success: The relative contributions of five social/personality factors, five cognitive/learning factors, and SAT scores. Journal of Education and Training Studies, 2(4), 46-58. https://doi.org/10.11114/jets.v2i4.451

Hayes, A. F. (2013). Introduction to mediation, moderation, and conditional process analysis: A regression-based approach. Guilford Press.

Holland, B. S., \& Copenhaver, M. D. (1988). Improved Bonferronitype multiple testing procedures. Psychological Bulletin, 104(1), 145-149. https://doi.org/10.1037/0033-2909.104.1.145

Kabat-Zinn, J. (1994). Wherever you go, there you are: Mindfulness meditation in everyday life. Hyperion.

Kaiser, R. H., Andrews-Hanna, J. R., Metcalf, C. A., \& Dimidjian, S. (2015). Dwell or decenter? Rumination and decentering predict working memory updating after interpersonal criticism. Cognitive Therapy and Research, 39(6), 744-753.

Lin, X., Lu, D., Huang, Z., Chen, W., Luo, X., \& Zhu, Y. (2019). The associations between subjective and objective cognitive functioning across manic or hypomanic, depressed, and euthymic states in Chinese bipolar patients. Journal of Affective Disorders, 249, 73-81. https://doi.org/10.1016/j.jad.2019.02.025

Lindsay, E. K., \& Creswell, J. D. (2017). Mechanisms of mindfulness training: Monitor and acceptance theory (MAT). Clinical Psychology Review, 51, 48-59. https://doi.org/10.1016/j.cpr.2016.10.011

Lloyd, M., Szani, A., Rubenstein, K., Colgary, C., \& Pereira-Pasarin, L. (2016). A brief mindfulness exercise before retrieval reduces recognition memory false alarms. Mindfulness, 7(3), 606-613. https://doi.org/10.1007/s12671-016-0495-y

Lyvers, M., Makin, C., Toms, E., Thorberg, F. A., \& Samios, C. (2014). Trait mindfulness in relation to emotional self-regulation and executive function. Mindfulness, 5(6), 619-625. https://doi.org/ 10.1007/s12671-013-0213-y

May, R. W., Bauer, K. N., \& Fincham, F. D. (2015). School burnout: Diminished academic and cognitive performance. Learning and Individual Differences, 42, 126-131. https://doi.org/10.1016/j. lindif.2015.07.015

Medvedev, O. N., Norden, P. A., Krägeloh, C. U., \& Siegert, R. J. (2018). Investigating unique contributions of dispositional mindfulness facets to depression, anxiety, and stress in general and student populations. Mindfulness, 9(6), 1757-1767. https://doi. org/10.1007/s12671-018-0917-0

Mesmer-Magnus, J., Manapragada, A., Viswesvaran, C., \& Allen, J. W. (2017). Trait mindfulness at work: A meta-analysis of the personal and professional correlates of trait mindfulness. Human
Performance, 30(2-3), 79-98. https://doi.org/10.1080/08959285. 2017.1307842

Mrazek, M. D., Franklin, M. S., Phillips, D. T., Baird, B., \& Schooler, J. W. (2013). Mindfulness training improves working memory capacity and GRE performance while reducing mind wandering. Psychological Science, 24(5), 776-781. https://doi.org/10.1177/ 0956797612459659

Napora, L. (2013). The impact of classroom-based meditation practice on cognitive engagement, mindfulness and academic performance of undergraduate college students (publication number 3598720) [Ph.D., State University of New York at Buffalo]. Publicly available content database. Ann Arbor. https://www.proquest.com/ openview/355c5d5bd9e8fe67e00df33bc3fe8a25/1

Oman, D., Shapiro, S. L., Thoresen, C. E., Plante, T. G., \& Flinders, T. (2008). Meditation lowers stress and supports forgiveness among college students: A randomized controlled trial. Journal of American College Health, 56(5), 569-578. https://doi.org/10.3200/jach. 56.5.569-578

Palmer, A., \& Rodger, S. (2009). Mindfulness, stress, and coping among university students. Canadian Journal of Counselling / Revue Canadienne de Counseling, 43(3), 198-212 https://cjc-rcc. ucalgary.ca/article/view/59019

Palmer, L. K., Economou, P., Cruz, D., Abraham-Cook, S., Huntington, J. S., Maris, M., Makhija, N., Welsh, T., \& Maley, L. (2014). The relationship between stress, fatigue, and cognitive functioning. College Student Journal, 48(1), 198-211 https://eric.ed.gov/?q= stress+AND+fatigue\&id=EJ1034199

Plant, E. A., Ericsson, K. A., Hill, L., \& Asberg, K. (2005). Why study time does not predict grade point average across college students: Implications of deliberate practice for academic performance. Contemporary Educational Psychology, 30(1), 96-116. https:// doi.org/10.1016/j.cedpsych.2004.06.001

Pluck, G., Ruales-Chieruzzi, C. B., Paucar-Guerra, E. J., AndradeGuimaraes, M. V., \& Trueba, A. F. (2016). Separate contributions of general intelligence and right prefrontal neurocognitive functions to academic achievement at university level. Trends in Neuroscience and Education, 5(4), 178-185. https://doi.org/10. 1016/j.tine.2016.07.002

Salmon, P. G., Sephton, S. E., \& Dreeben, S. J. (2011). Mindfulnessbased stress reduction. In J. D. Herbert \& E. M. Forman (Eds.), Acceptance and mindfulness in cognitive behavior therapy: Understanding and applying the new therapies (pp. 132-163). Wiley. https://doi.org/10.1002/9781118001851.ch6

Schanche, E., Vøllestad, J., Binder, P. E., Osnes, B., Visted, E., Svendsen, J. L., \& Sørensen, L. (2020). Can clinical psychology students benefit from brief and intensive mindfulness training? Counselling and Psychotherapy Research, 20(2), 311-324. https://doi.org/10. 1002/capr.12273

Shapiro, S. L., Brown, K. W., Thoresen, C., \& Plante, T. G. (2011). The moderation of mindfulness-based stress reduction effects by trait mindfulness: Results from a randomized controlled trial. Journal of Clinical Psychology, 67(3), 267-277. https://doi.org/10.1002/ jclp.20761

Son, C., Hegde, S., Smith, A., Wang, X., \& Sasangohar, F. (2020). Effects of COVID-19 on college students' mental health in the United States: Interview survey study. Journal of Medical Internet Research, 22(9), e21279. https://doi.org/10.2196/21279

Struthers, C. W., Perry, R. P., \& Menec, V. H. (2000). An examination of the relationship among academic stress, coping, motivation, and performance in college. Research in Higher Education, 41(5), 581-592. https://doi.org/10.1023/a:1007094931292

Wang, X., Hegde, S., Son, C., Keller, B., Smith, A., \& Sasangohar, F. (2020). Investigating mental health of US college students during the COVID-19 pandemic: Cross-sectional survey study. Journal of Medical Internet Research, 22(9), e22817. https://doi.org/10. 2196/22817 
Weis, R., Ray, S. D., \& Cohen, T. A. (2021). Mindfulness as a way to cope with COVID-19-related stress and anxiety. Counselling and Psychotherapy Research, 21(1), 8-18. https://doi.org/10.1002/ capr.12375

Yamada, K., \& Victor, T. L. (2012). The impact of mindful awareness practices on college student health, well-being, and capacity for learning: A pilot study. Psychology Learning \& Teaching, 11(2), 139-145. https://doi.org/10.2304/plat.2012.11.2.139

Zimmaro, L. A., Salmon, P., Naidu, H., Rowe, J., Phillips, K., Rebholz, W. N., Giese-Davis, J., Cash, E., Dreeben, S. J., Bayley-Veloso, R.,
Jablonski, M. E., Hicks, A., Siwik, C., \& Sephton, S. E. (2016). Association of dispositional mindfulness with stress, cortisol, and well-being among university undergraduate students. Mindfulness, 7(4), 874-885. https://doi.org/10.1007/s12671-016-0526-8

Publisher's Note Springer Nature remains neutral with regard to jurisdictional claims in published maps and institutional affiliations. 